\title{
"Kurdistan" Technique for the Treatment of Unprotected Trifurcation Left Main Stem Coronary Artery Lesion: Case Report
}

\author{
Aram J. Mirza \\ Department of Cardiology, Sulaimany Cardiac Hospital, Sulaimany, Iraq \\ Email: arammerza@ymail.com
}

Received 6 May 2014; revised 1 July 2014; accepted 22 July 2014

Copyright (C) 2014 by author and Scientific Research Publishing Inc.

This work is licensed under the Creative Commons Attribution International License (CC BY). http://creativecommons.org/licenses/by/4.0/

(c) (i) Open Access

\section{Abstract}

The left main coronary artery (LMCA) is responsible for supplying about $75 \%$ to $100 \%$ of the left ventricular cardiac mass. Left main stem coronary artery (LMCA) disease reduces flow to a large portion of the myocardium, placing the patient at high risk for life-threatening events such as left ventricular dysfunction and arrhythmias with a high mortality approaching $50 \%$ in those treated medically. For several decades, coronary artery bypass grafting (CABG) has been considered as a gold standard treatment of unprotected left main coronary artery (ULMCA). However, successful percutaneous coronary interventions (PCI) have been increasingly reported recently due to improved stent technology and better operator expertise. In spite of these factors, management can be challenging especially in LMCA bifurcational \& trifurcational lesions, and therefore an integrated approach combining special techniques, physiological evaluation and adjunctive pharmacological agents should be combined for better clinical outcome. Herein, we describe a new promising technique named (Kurdistan technique) for the treatment of trifurcation unprotected left main stem lesion. In the last 18 months, 21 patients with significant trifurcational LMS had underwent PCI using this technique in our hospital (Sulaimany Heart Hospital/Kurdistan). The procedural success rate was $100 \%$, follow up coronary angiography done between 6 - 12 months after the procedure for all the patients with no significant in-stent restenosis in any patient. One case is presented here demonstrating the technique.

\section{Keywords}

LMS, DES, Trifurcational 


\section{Introduction}

Significant unprotected left main coronary artery disease (LMCA) occurs in 5\% - 10\% of patients undergoing coronary angiography [1] [2]. Serruys reported that revascularization with PCI has comparable safety and efficacy outcomes to CABG for patients with LMCA disease [3].

The LMCA is generally divided into three anatomic regions: The ostium or the origin of the LMCA from the aorta, amid portion and the distal portion. Left main trifurcating coronary artery disease (LMTCAD) is a complex and challenging anatomy to treat percutaneously.

The clinical indicators of LMCA stenosis are easily recognized and include a crescendo pattern of angina pectoris, an electrocardiogram ECG with ST-segment depression with pain or with simultaneous anterior or inferior ST segment changes and fluoroscopic calcification of the LMCA [4]. These indicators are not specific and the gold standard for treatment is coronary angiography.

Several recent large registries and randomized controlled trials such as the MAIN-COMPARE (Revascularization for Unprotected Left Main Coronary Artery Stenosis: Comparison of Percutaneous Coronary Angioplasty Versus Surgical Revascularization) registry, SYNTAX (Synergy between PCI with TAXUS and Cardiac Surgery), and PRECOMBAT (Premier of Randomized Comparison of Bypass Surgery versus Angioplas Ty Using Sirolimus-Eluting Stent in Patients with Left Main Coronary Artery Disease) randomized trials have demonstrated that LMCA stenting yields comparable mortality and morbidity rates to CABG. [5]-[7], in addition several observational studies revealed that the early clinical events of LMCA stenting were similar or superior to those of CABG because of significant increase in periprocedural myocardial infarction (MI) or stroke in CABG patients, and that mortality between 30 days and 3 years was similar in both the Groups [8]. However, the risk of target vessel revascularization was higher with PCI than CABG [9]-[11].

Several modifiable procedural factors need to be addressed to achieve better outcomes of LMCA stenting, the intravascular ultrasound (IVUS) provides accurate information about stent sizing and helps to detect suboptimal stent deployment or stent-related complications, thereby making LMCA PCI safer and more effective. Previously, the MAIN-COMPARE registry, and more recently, the de la Torre Hernandez et al. [12] study, demonstrated that IVUS-guided LMCA stenting is associated with less mortality [12] [13]. Second, for the distal left main disease, the PCI strategy may affect the prognosis. In general, the single-stent technique clearly shows more favorable long-term clinical outcomes compared with the 2-stent technique, even in true bifurcation stenosis [14].

Physiological assessment fractional flow reserve (FFR) of the lesion is also to be considered during LMCA PCI. Several studies already demonstrated that FFR-guided decision making for the treatment of LMCA is associated with favorable prognosis and the intermediate LMCA lesion with FFR 1/4 0.75 to 0.80 could be safely deferred [15].

In addition, for LMCA stenosis, if FFR measurement is not feasible, the IVUS minimal lumen area (1/4 4.8 $\mathrm{mm}^{2}$ ) could be used as a definition of significant functional stenosis [16].

For risk stratification for procedural and long-term outcomes combination of SYNTAX and the Euro SCORE into a common risk model (Global Risk Classification) was correlated with a significant improvement in predicting cardiac mortality in patients undergoing PCI for LMCA [17]. Another score, the New Risk Stratification Score showed a higher sensitivity and specificity to predict clinical outcome [18].

Kurdistan technique consist of simultaneous stent implantation for LMS-ramus intermedius branch \& LMS-left circumflex (LtCx) artery both should be localized ostialy with $1 \mathrm{~mm}$ protrusion to the LMS, meanwhile keeping balloon in LMS - left anterior descending (LAD) artery after LMS-LAD stenting, then simultaneous inflation of three balloons to variable atmospheres.

\section{Case}

A 56-year-old hypertensive, non-diabetic, ex-smoker male patient presented with Canadian Cardiovascular Society (CCS) class III-IV angina, his baseline ECG \& trans-thoracic echocardiography were non-significant for ischemia. Angiography demonstrated diseased distal left main stem( LMS) with about 40\% - 50\% stenosis, critical ostial \& proximal LAD lesion, significant ostial left circumflex (LtCx) \& 95\% ostial ramus intermedius lesion, the LMS was $4.1 \mathrm{~mm}$ in diameter \& proximal LAD was $3.8 \mathrm{~mm}$ (Figure 1(a) \& Figure 1(b)).

The LAD, LtCx \& ramus intermedius were wired with floppy wires (Balance Middle Weight Universal (BMW) Abbott Vascular, Santa Clara, USA), the LMS-LAD pre-dilated with $3.0 \times 15$ mm balloon at 16 atm. 
Ramus intermedius was predilated with $2.5 \times 15 \mathrm{~mm}$ non-compliant (NC) at 14 atm.

The LMS-LAD was stented with Resolute Integrity stent (Zatrolilimus-Eluting, Medtronic, Minneapolis, USA) $4.0 \times 18 \mathrm{~mm}$ at 14 atm (Figure 2). Second stent Resolute Integrity stent (Zatrolilimus-Eluting, Medtronic, Minneapolis, USA) $3.5 \times 26 \mathrm{~mm}$ at 14 atm implanted distally with $1 \mathrm{~mm}$ overlap with proximal stent, ballooning done in-between two stents at 16 atm (Figure 3 and Figure 4).

Re-wiring done for the LMS-ramus intermedius \& LMS-LtCx through stent struts with floppy wires (Balance Middle Weight Universal (BMW), Abbott Vascular, Santa Clara, USA) \& kissing ballooning done for LMSLAD, LMS-ramus Intermedius \& LMS-LtCx with balloons $(3.5 \times 15$ mm, $2.75 \times 15$ mm \& $2.75 \times 15$ mm) consecutively with simultaneous inflation at first between LMS-LAD Vs. LMS-ramus intermedius 14 Vs. 12 atm, then LMS-ramus intermedius \& LMS-LtCx 12 Vs. 12 atm simultaneous inflation \& then between LMS-LAD Vs. LMS-ramus intermedius Vs. LMS-LtCx at 14 Vs. 12 VS 12 atm simultaneous inflations (Figure 5).

Angiography done shows dissection in the ostium of ramus intermedius (Figure 6) \& proven by IVUS (Figure 7).

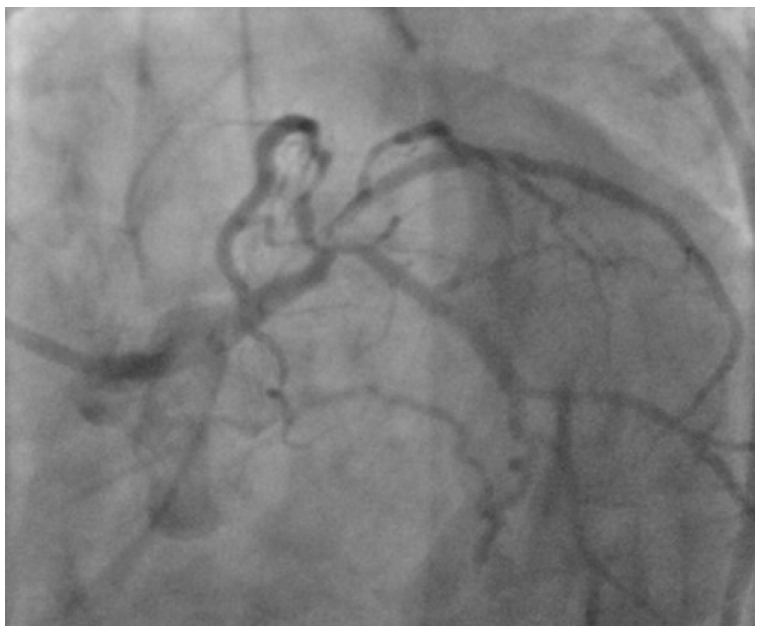

(a)

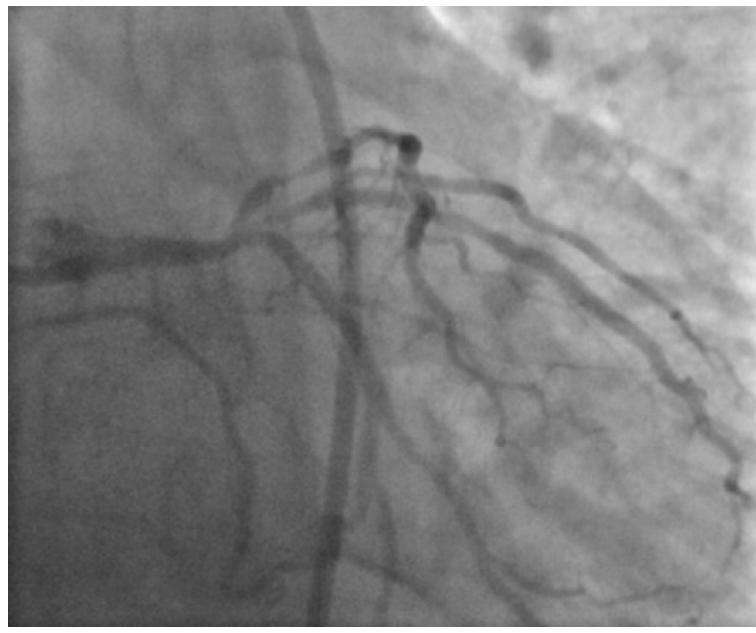

(b)

Figure 1. It shows critical distal LMS, ostial \& proximal LAD lesion, critical ostial \& significant ostial LtCx lesion in LAO-CAU \& PA-CAU projections.

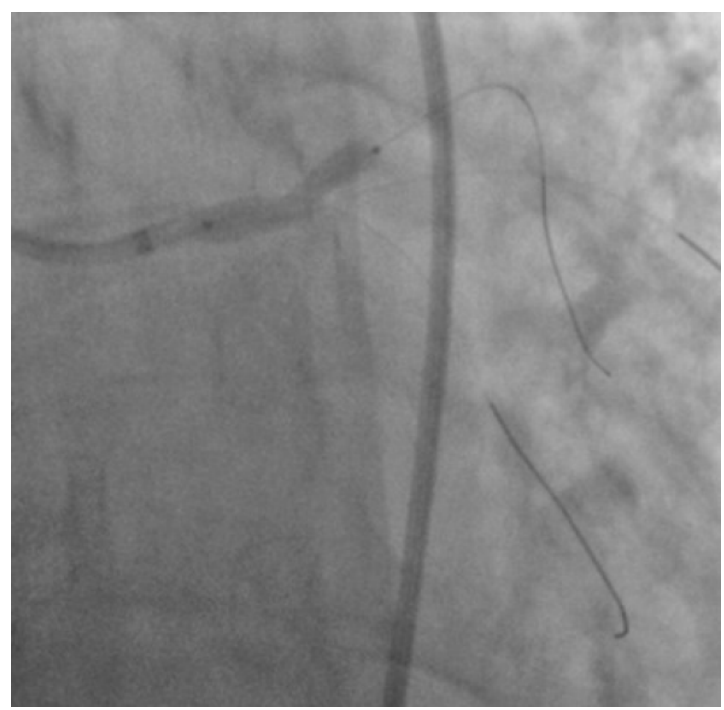

Figure 2. It shows stenting for LMS-LAD with $(4.0 \times$ $18 \mathrm{~mm}$ ) DES $16 \mathrm{~atm}$. with $1 \mathrm{~mm}$ overlap with the proxymal stent. 


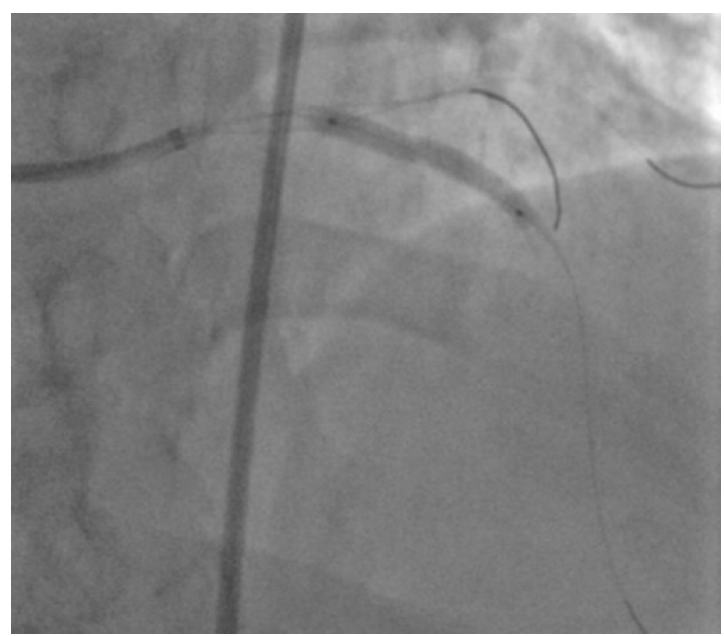

Figure 3. It shows ballooning in-between 2 stents after implantation of $(3.5 \times 26 \mathrm{~mm}) \mathrm{DES}$ in proximal LAD.

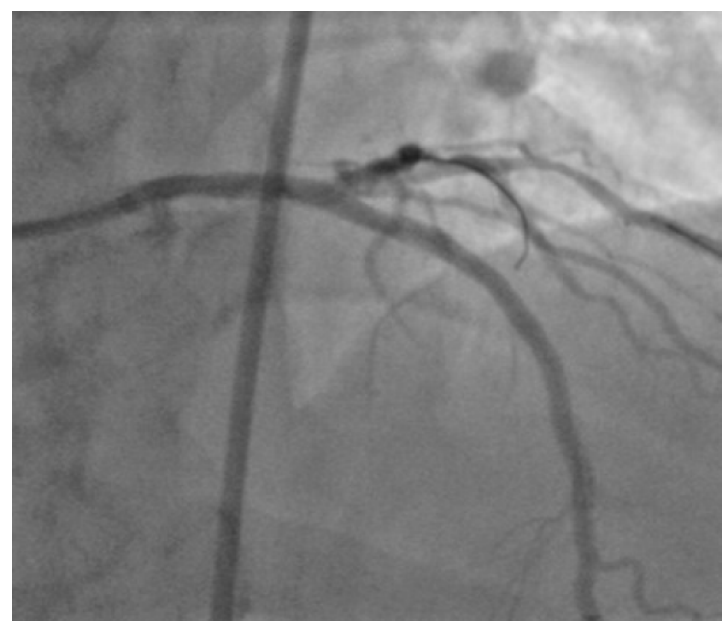

Figure 4. It shows LMS \& proximal LAD after stenting. $\mathrm{LtCx}$ to variable atmospheres.

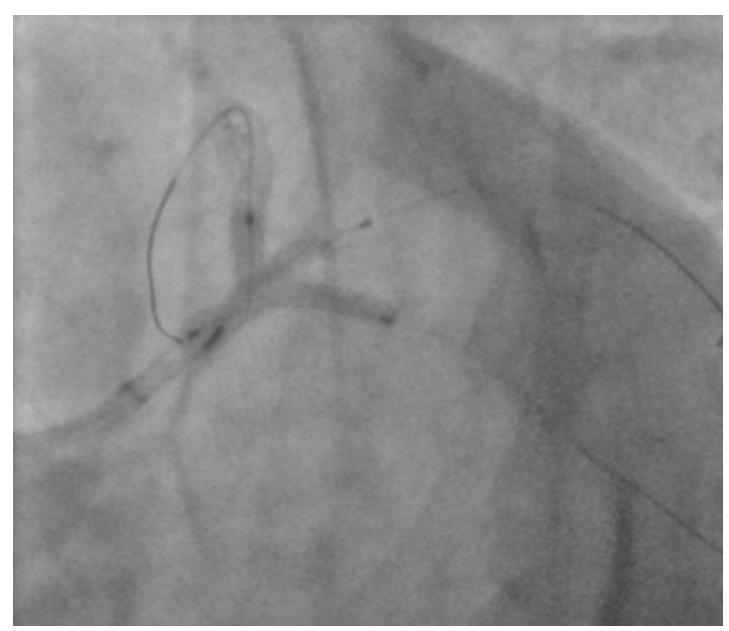

Figure 5. It shows simultaneous kissing stenting between LMS-LAD Vs. LMS-ramus intermedius \& LMS. 


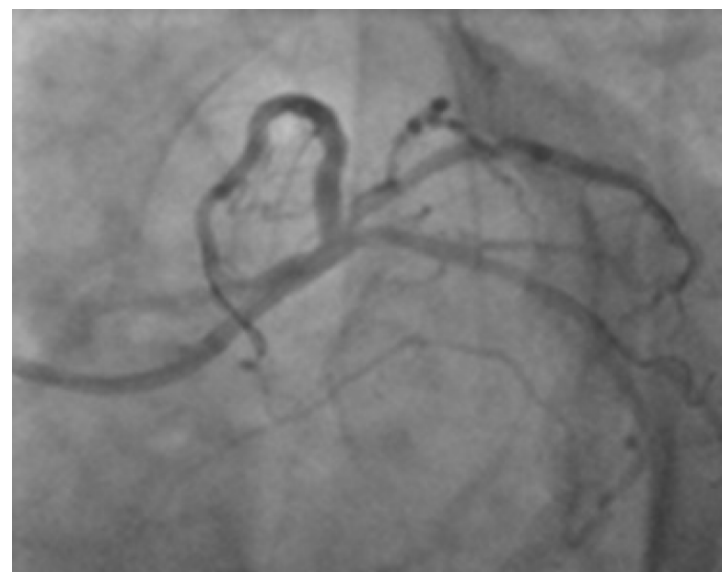

Figure 6. It shows dissection of ostial ramus intermedius after ballooning.

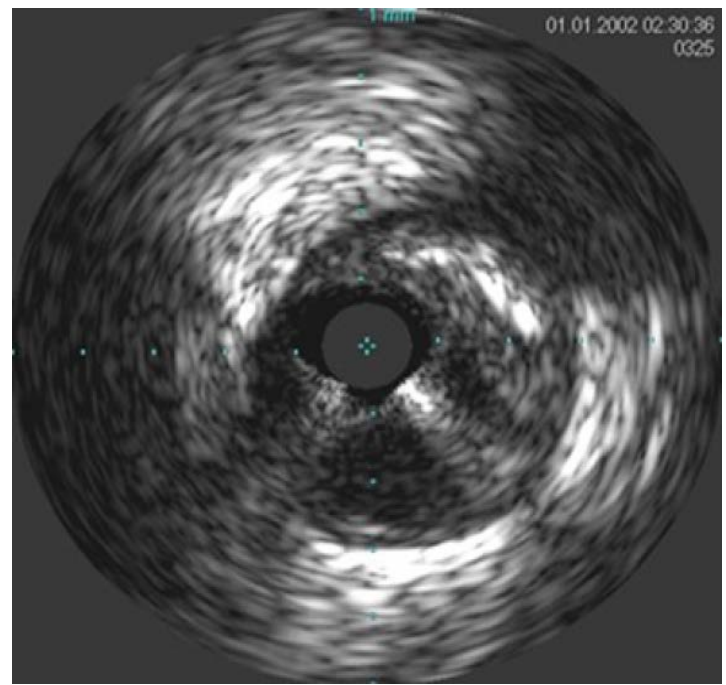

Figure 7. IVUS showing the ostial ramus intermedius.

\section{Technique:}

A new technique (Kurdistan technique) was used for trifurcation ULMCA stenting, Resolute Integrity stent (Zatrolilimus-Eluting, Medtronic, Minneapolis, USA) $(2.75 \times 15 \mathrm{~mm})$ localized in the ostial ramus intermedius with $1 \mathrm{~mm}$ protrusion to the LMS \& another stent Resolute Integrity (Zatrolilimus-Eluting, Medtronic, Minneapolis, USA) $(3.0 \times 15 \mathrm{~mm})$ localized in the ostial LtCx with $1 \mathrm{~mm}$ protrusion to the LMS, meanwhile $(3.5 \times 20$ $\mathrm{mm}$ ) non-compliant balloon placed in the LMS-LAD after stenting for LMS-LAD, simultaneous inflation for both stents done at 14 atm both (Figure 8), after that both balloons were withdrawn to the LMS-ramus intermedius \& LMS-LtCx consecutively, then simultaneous inflation done between LMs-LAD Vs. LMS-ramus intermedius Vs. LMS-LtCx at 14 Vs, 12 Vs. 12 atm simultaneously (Figure 9) with good final results (Figure 10(a) and Figure 10(b)).

\section{Discussion}

True distal bifurcation lesions may be treated by either a single-stent or by a two-stent strategy. Choice of strategy is based on vessel and lesion characteristics.

Choice of strategy is based on vessel and lesion characteristics (plaque distribution, the diameter of the branches and the angle between them, anatomy of the side branch) but also on operator's experience.

For distal left main stenosis, stenting across the bifurcation toward the left anterior descending was performed 


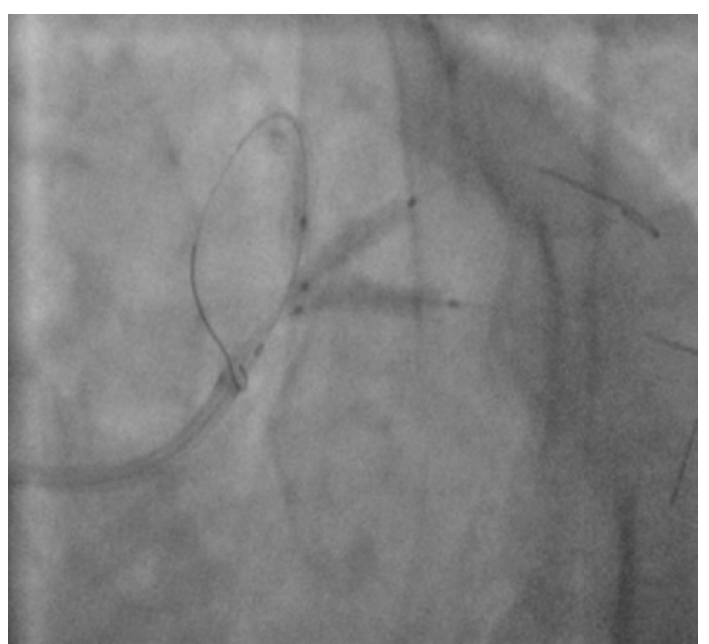

Figure 8. It shows Kurdistan technique; simulta-neous 2 stent implantation in the ostial LtCx \& ostial ramus intermedius with $1 \mathrm{~mm}$ protrusion to LMS both, meanwhile keeping NC balloon in LMS-LAD.

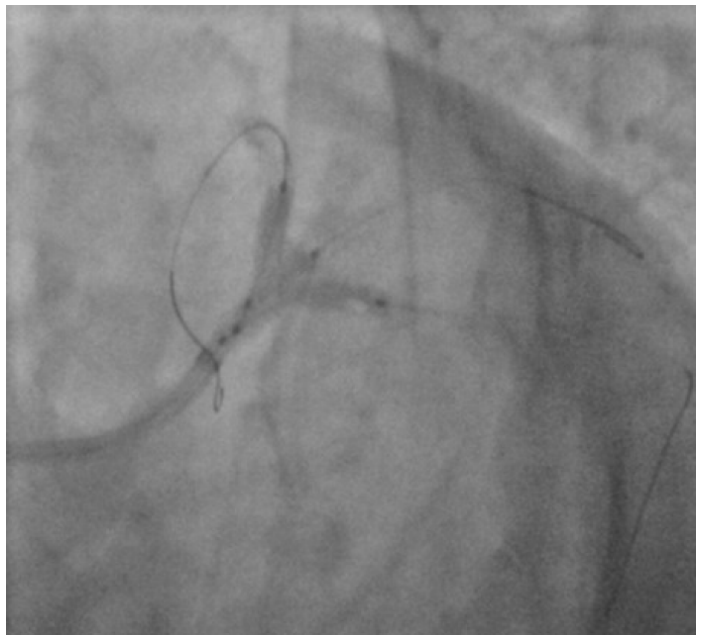

Figure 9. It shows kissing inflation between LMs-LAD Vs. LMS-ramus intermedius Vs. LMS-LtCx to variable atmospheres.

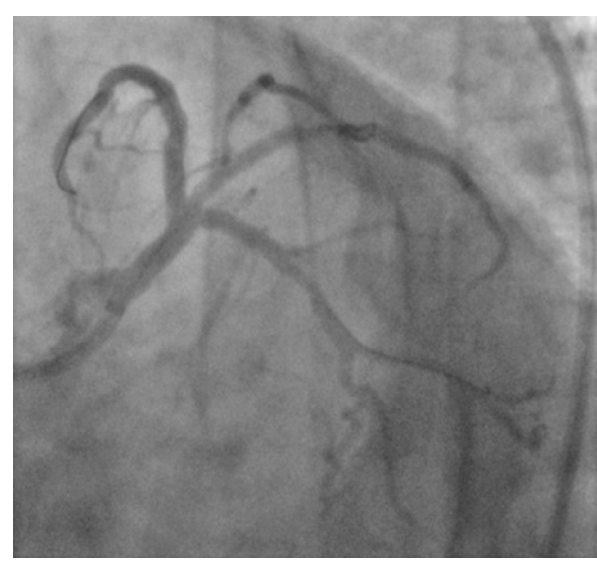

(a)

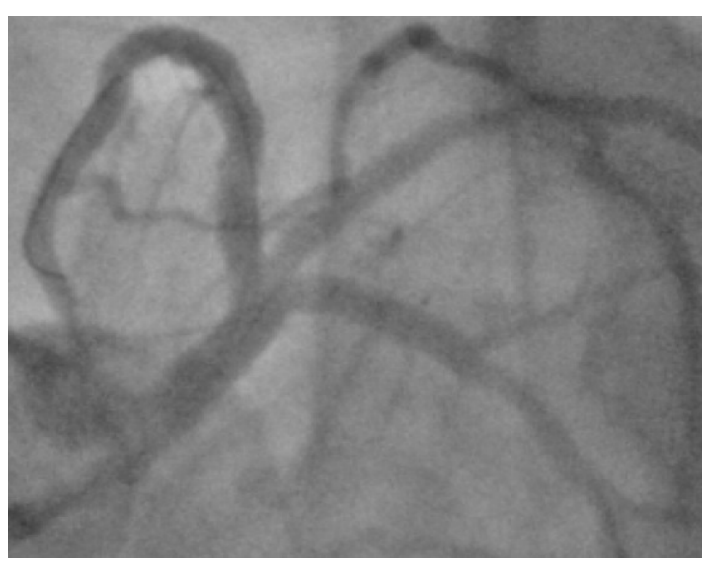

(b)

Figure 10. It shows final results. 
first, and then provisional stenting of the circumflex artery with T-stenting or "culotte" technique was preferred.

Post-dilation with kissing balloon angioplasty was always used to finish the distal left main stenting procedure [19].

The provisional stenting is a single-stentstrategy, although it allows the placement of a second stent if required [T, $\mathrm{T}$ and protrusion (TAP), culotte techniques]. More complex lesions may require double-stent strategy (T stenting, TAP, crush, culotte, V stenting).

\subsection{Double-Stent Strategies}

\subsubsection{The Culotte Stenting}

This is a strategy suitable for lesions where the ostium of the $\mathrm{LtCx}$ is diseased, the angulation between the vessels is 60 - 80 (higher risk of plaque shift), and the two vessels are of similar diameter.

This technique provides an optimal reconstruction of distal LMS bifurcation but with a significant area of stent overlap.

\subsubsection{The T Stenting}

The $\mathrm{T}$ stent is used when a two-stent strategy is required but the angulation between the two vessels approached 90.

This technique provides a good reconstruction of T shape distal LMS bifurcation but with the risk of leaving the side branch ostiumun covered (side branch stent to distal) or of placing the side branch stent to proximal protruding in the LM stent.

\subsubsection{The T and Protrusion (TAP) Technique}

This technique can be used in the majority of the bifurcation lesions. It can provide a good reconstruction of distal LMS bifurcation with minimal stent overlap.

\subsubsection{The Crush Stenting}

The crush technique can be used when the diameter of the main vessel is greater than the side branch and the angulation is favorable (approximately $\leq 60 \%$ ). The side branch is stented first, positioning the stent to allow 1 $2 \mathrm{~mm}$ (mini-crush) to protrude into the LM.

\subsubsection{The V Stenting}

The V stent technique (or "kissing stent" technique) is mainly used inMedina 0, 1, 1 lesion that can be treated with a minimal and very shortneo-carina [20].

LM trifurcation disease is typically treated surgically, particularly when the LM artery is involved, therefore its percutaneous treatment is generally reserved to high-volume centers performing complex coronary interventions.

There are 2 types of left main trifurcation diseased:

Type A, involving the main trunk with extension to one or more of the origin of the branches; [21].

Type B, involving the origin of one or more of the main branches without extension to the main trunk (MT)

In our cases, special new technique is used for treatment of Trifurcational LM lesion, the initial steps were similar to traditional stenting which is stenting LMS-LAD, then rewiring of 2 side branches and then kissing ballooning between three (main trunk \& two side branches) with simultaneous inflations between all three, when decision for stenting of the side branches is taken then two stent will be placed in the ostium of both side branches with minimal protrusion to the LMS, with concomitant placement of a balloon in the LMS-LAD, both stents are inflated simultaneously, then both balloons are withdrawn to the LMS \& simultaneous kissing inflation done between all three.

\section{Conclusions}

LM trifurcation stenting carries an overall high rate of adverse events, mostly driven by a high target lesion revascularization (TLR) rate. Type A lesions and the number of stents placed predicted a higher combined endpoint of death, nonfatal MI and TLR. By logistic regression analysis, Type A lesions are the only independent 
predictors of the primary outcome.

This technique (Kurdistan technique) for treatment of unprotected trifurcation LMS lesion seems to be promising provided that it is conducted by experienced operator in high-volume centers performing complex coronary intervention. Intravascular imaging is a key for successful and optimum final results.

\section{References}

[1] Stone, P. and Goldschlager, N. (1979) Left Main Coronary Artery Disease: Review and Appraisal. Cardiovascular Medicine, 4, 165-177.

[2] Demos, H., Rosch, J. and McAnulty, J. (1977) Left Maincoronary Artery Disease. Cardiovascular Clinics, 8:20111.364:1718-27.

[3] Serruys, P.W. (2011) Four-Year Follow-Up of the SYNTAX Trial: Optimal Revascularization Strategy in Patients with Left Main Disease. Journal of the American College of Cardiology, 58, B15.

[4] Plotnick, G.D., Greene, H.L., Carliner, N.H., et al. (1979) Clinical Indicators of LM Coronary Artery Disease in Unstable Angina. Annals of Internal Medicine, 91,149-153. http://dx.doi.org/10.7326/0003-4819-91-2-149

[5] Seung, K.B., Park, D.W., Kim, Y.H., et al. (2008) Stents versus Coronary-Arterybypass Grafting for Left Main Coronary Artery Disease. The New England Journal of Medicine, 358, 1781-1792. http://dx.doi.org/10.1056/NEJMoa0801441

[6] Morice, M.C., Serruys, P.W., Kappetein, A.P., et al. (2014) Five-Year Outcomes in Patients with Left Main Disease Treated with Either Percutaneous Coronary Intervention or Coronary Artery Bypass Grafting in the SYNTAX Trial. Circulation, 129, 2388-2394. http://dx.doi.org/10.1161/CIRCULATIONAHA.113.006689

[7] Park, S.J., Kim, Y.H., Park, D.W., et al. (2011) Randomized Trial of Stents versus Bypass Surgery for Left Main Coronary Artery Disease. The New England Journal of Medicine, 364, 1718-1727. http://dx.doi.org/10.1056/NEJMoa1100452

[8] Seung, K.B., Park, D.W., Kim, Y.H., et al. (2008) Stents versus Coronary Artery Bypass Grafting for Left Main Coronary Artery Disease. The New England Journal of Medicine, 358, 1781-1792. http://dx.doi.org/10.1056/NEJMoa0801441

[9] Chieffo, A., Morici, N., Maisano, F., et al. (2006) Percutaneous Treatment with Drug-Eluting Stent Implantation versus Bypass Surgery for Unprotected Left Main Stenosis: A Single-Centre Experience. Circulation, 113, 2542-2547. http://dx.doi.org/10.1161/CIRCULATIONAHA.105.595694

[10] Lee, M.S., Kapoor, N., Jamal, F., et al. (2006) Comparison of Coronary Artery Bypass Surgery with Percutaneous Coronary Intervention with Drug-Eluting Stents for Unprotected Left Main Coronary Disease. Journal of the American College of Cardiology, 47, 864-870. http://dx.doi.org/10.1016/j.jacc.2005.09.072

[11] Park, D.W., Seung, K.B., Kim, Y.H., et al. (2010) Long-Term Safety and Efficacy of Stenting versus Coronary Artery Bypass Grafting for Unprotected Left Main Coronary Artery Disease: 5-Year Results from the MAIN-COMPARE (Revascularization for Unprotected Left Main Coronary Artery Stenosis; Comparison of Percutaneous Coronary Angioplasty versus Surgical Revascularization) Registry. Journal of the American College of Cardiology, 56, 117-127. http://dx.doi.org/10.1016/j.jacc.2010.04.004

[12] de la Torre Hernandez, J.M., Baz Alonso, J.A., Gómez Hospital, J.A., et al. (2014) Clinical Impact of Intravascular Ultrasound Guidance in Drug-Eluting Stent Implantation for Unprotected Left Main Coronary Disease: Pooled Analysis at the Patient-Level of 4 Registries. JACC Cardiovascular Interventions, 7, 244-254.

[13] Park, S.J., Kim, Y.H., Park, D.W., et al. (2009) Impact of Intravascular Ultrasound Guidance on Long-Term Mortality in Stenting for Unprotected Left Main Coronary Artery Stenosis. Circulation: Cardiovascular Interventions, 2, 167177.

[14] Palmerini, T., Marzocchi, A., Tamburino, C., et al. (2008) Impact of Bifurcation Technique on 2-Year Clinical Outcomes in 773 Patients with Distal Unprotected Left Main Coronary Artery Stenosis Treated with Drug-Eluting Stents. Circulation: Cardiovascular Interventions, 1, 185-192.

[15] Park, S.J., Ahn, J.M. and Kang, S.J. (2012) Unprotected Left Main Percutaneous Coronary Intervention: Integrated Use of Fractional Flow Reserve and Intravascular Ultrasound. Journal of the American Heart Association, 1, Article ID: e004556. http://dx.doi.org/10.1161/JAHA.112.004556

[16] Kang, S.J., Lee, J.Y., Ahn, J.M., et al. (2011) Intravascular Ultrasound-Derived Predictors for Fractional Flow Reserve in Intermediate Left Main Disease. JACC Cardiovascular Interventions, 4, 1168-1174.

[17] Capodanno, D., Miano, M., Cincotta, G., et al. (2010) EuroSCORE Refines the Predictive Ability of SYNTAX Scoring Patients Undergoing Left Main Percutaneous Coronary Intervention. American Heart Journal, 159, 103-109. http://dx.doi.org/10.1016/j.ahj.2009.10.021 
[18] Chen, S.L., Chen, J.P., Mintz, G., et al. (2010) Comparison between the NERS (New Risk Stratification) and the SYNTAX (Synergy between Percutaneous Intervention with Taxus and Cardiac Surgery) Score in Outcome Prediction for Uncomplicated Left Main Stenting. JACC Cardiovascular Interventions, 3, 632-641. http://dx.doi.org/10.1016/j.jcin.2010.04.006

[19] Buszman, P.E., Kiesz, S.R. and Bochenek, A. (2008) Acute and Late Outcomes of Unprotected Left Main Stenting in Comparison with Surgical Revascularization. Journal of the American College of Cardiology, 51, 538-545.

[20] Chen, S.L., Zhang, J.J., Ye, F., et al. (2008) Study Comparing the Double Kissing (DK) Crush with Classical Crush for the Treatment of Coronary Bifurcation Lesions: The DKCRUSH-1 Bifurcation Study with Drug-Eluting Stents. European Journal of Clinical Investigation, 38, 361-371. http://dx.doi.org/10.1111/j.1365-2362.2008.01949.x

[21] Shammas, N.W. and Shammas, G.A. (2009) Treatment of Left Main Coronary Trifurcation Lesions with the Paclitaxel Drug-Eluting Stent: Mid-Term Outcomes from a Tertiary Medical Center. Journal of Invasive Cardiology, 21, 321325. 
Scientific Research Publishing (SCIRP) is one of the largest Open Access journal publishers. It is currently publishing more than 200 open access, online, peer-reviewed journals covering a wide range of academic disciplines. SCIRP serves the worldwide academic communities and contributes to the progress and application of science with its publication.

Other selected journals from SCIRP are listed as below. Submit your manuscript to us via either submit@scirp.org or Online Submission Portal.
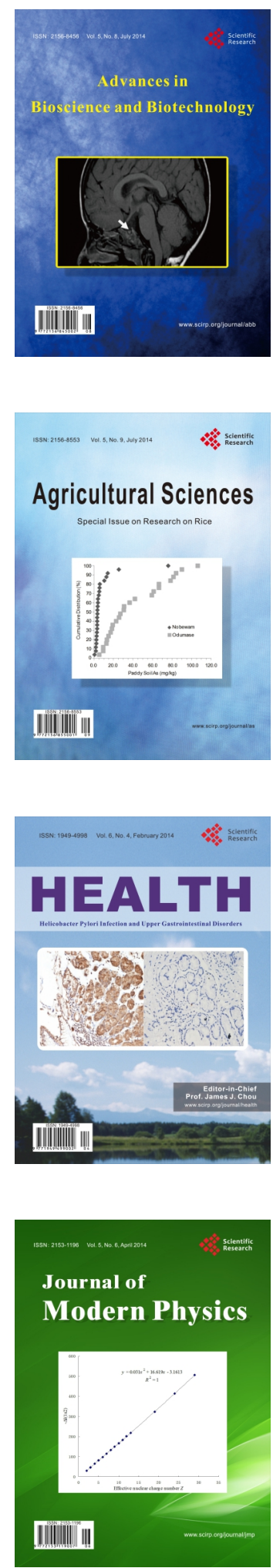
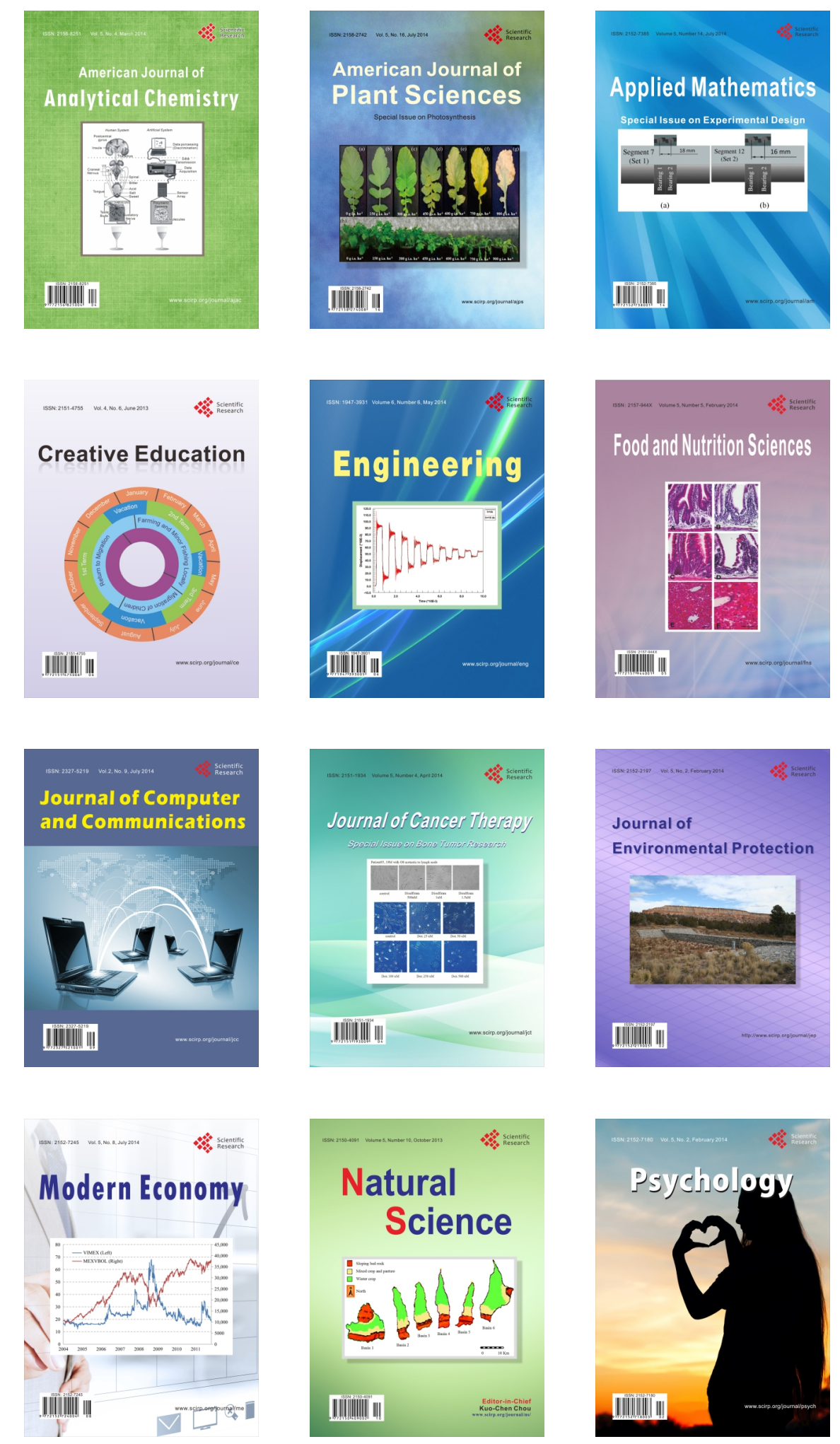